\title{
Prevalence of Human Coronaviruses in Adults With Acute Respiratory Tract Infections in Beijing, China
}

\author{
Lili Ren, ${ }^{1}$ Richard Gonzalez, ${ }^{1,2}$ Jin Xu, ${ }^{3}$ Yan Xiao, ${ }^{1}$ Yongjun Li, ${ }^{2}$ Hongli Zhou, ${ }^{1}$ Jianguo Li, ${ }^{1}$ \\ Qingqing Yang, ${ }^{1}$ Jing Zhang, ${ }^{1}$ Lan Chen, ${ }^{1}$ Wei Wang, ${ }^{1}$ Guy Vernet, ${ }^{2}$ Gláucia Paranhos-Baccalà, ${ }^{2}$ \\ Zhong Wang, ${ }^{1,3 * *}$ and Jianwei Wang ${ }^{1 *}$ \\ ${ }^{1}$ State Key Laboratory for Molecular Virology and Genetic Engineering and Dr. Christophe Mérieux Laboratory, IPB, \\ CAMS-Fondation Mérieux, Institute of Pathogen Biology (IPB), Chinese Academy of Medical Sciences (CAMS) \& Peking \\ Union Medical College, Beijing, China \\ ${ }^{2}$ Fondation Mérieux, Lyon, France \\ ${ }^{3}$ Peking Union Medical College Hospital, CAMS, Beijing, China
}

Human coronaviruses (HCoVs) are a common etiological agent of acute respiratory tract infections. HCoV infections, especially those caused by the two HCoVs identified most recently, NL63 and HKU-1, have not been characterized fully. To evaluate the prevalence and clinical presentations of HKU1 and NL63 in adults with acute respiratory tract infections, an investigation of $\mathrm{HCoV}$ infections in Beijing, China from 2005 to 2009 was performed by using reverse transcriptase PCR assays and sequencing analysis. Among 8,396 respiratory specimens studied, 87 (1\%) clinical samples were positive for HCoVs, of which 50 samples $(0.6 \%$ of the total) were positive for HCoV-OC43, $15(0.2 \%)$ for HCoV-229E, 14 $(0.2 \%)$ for HCoV-HKU1, and $8(0.1 \%)$ for HCoVNL63. The prevalence of HCoV infection in adults exhibited distinct seasonal fluctuations during the study period. In addition, patients positive for HCoV-229E infections were more likely to be coinfected with other respiratory viruses. Enterovirus, rhinovirus, and parainfluenza virus type 3 were the most common viruses found in patients with $\mathrm{HCoV}$ infections. The demographic and clinical data present in this study of $\mathrm{HCoV}$ infections in adults with acute respiratory tract infections should improve our understanding of the pathogenesis of HCoVs. J. Med. Virol. 83:291-297, 2011. ๑ 2010 Wiley-Liss, Inc.

KEY WORDS: human coronavirus; respiratory tract infection; epidemiology

\section{INTRODUCTION}

Coronaviruses $(\mathrm{CoVs})$ are enveloped viruses with large positive-sense, single-stranded RNA genomes. They cause a wide range of illnesses including respira- tory tract infections, diarrhea, and disorders of the central nervous system in birds, humans, and other mammals [Holmes, 2001]. Based on genome sequence and serology, CoVs can be divided into three distinct groups, I, II, and III. Human $\mathrm{CoVs}$ (HCoVs) belong to group I and II [Lai and Cavanagh, 1997; Woo et al., 2009]. The first two identified $\mathrm{HCoVs}$ were $\mathrm{HCoV} 229 \mathrm{E}$ and OC43 [Tyrrell and Bynoe, 1965; Hamre and Procknow, 1966; McIntosh et al., 1967].

Due to the outbreak of severe acute respiratory syndrome (SARS) caused by a $\mathrm{CoV}$ (SARS-CoV) in 2003, these viruses have garnered renewed interest in the scientific community. Novel $\mathrm{HCoV}$ s are continuously being identified with the help of advancing molecular techniques [Drosten et al., 2003; Kuiken et al., 2003; Gibbs et al., 2004; Woo et al., 2009]. Two novel HCoVs, NL63, a group I CoV [Fouchier et al., 2004; van der Hoek et al., 2004], and HKU1, a group II CoV [Woo et al., 2005], were identified first in respiratory tract samples in the Netherlands and Hong Kong. All of the HCoVs found to date are reported to be associated with acute respiratory tract infections.

The authors report no conflicts of interest in the publication of this article.

Grant sponsor: National Major Science and Technology Research Projects for the Control and Prevention of Major Infectious Diseases in China; Grant number: 2009ZX10004-206; Grant sponsor: Fondation Merieux; Grant sponsor: Institute of Pathogen Biology, Chinese Academy of Medical Sciences \& Pecking Union Medical College.

*Correspondence to: Jianwei Wang, 9\# Dong Dan San Tiao, Dongcheng District, Beijing 100730, China.

E-mail: wangjw28@ipbcams.ac.cn

**Correspondence to: Zhong Wang, 1\# Shuai Fu Yuan, Dongcheng District, Beijing 100730, China.

E-mail: wangzhong523@vip.163.com

Accepted 25 August 2010

DOI 10.1002/jmv.21956

Published online in Wiley Online Library

(wileyonlinelibrary.com). 
$\mathrm{HCoV}$ infections can present clinical symptoms ranging from a mild cold to severe lower respiratory tract infections such as pneumonia [Esper et al., 2005; van der Hoek 2007; Perlman and Netland, 2009]. The roles of $\mathrm{HCoVs}$ have been investigated in patients with more severe clinical symptoms caused by $\mathrm{HCoV}$ infection, such as in children, elderly adults, immunocompromised adults, and the patients with severe disease symptoms [Varkey and Varkey, 2008; van der Hoek et al., 2007; Gorse et al., 2009; Perlman and Netland, 2009]. Seroepidemiological studies have shown a trend of steady increased incidence of IgG antibodies against non-SARS HCoVs, with about $70 \%$ of healthy adults being detected seropositive for the virus [McIntosh et al., 1970; Shao et al., 2007; Dijkman et al., 2008; Chan et al., 2009], suggesting the wide spread of $\mathrm{HCoV}$ infections in human populations. However, the clinical significance of non-SARS $\mathrm{HCoV}$ infections, in particular the novel HCoVs found recently, has not been fully addressed.

To evaluate the prevalence and clinical presentations of $\mathrm{HCoV}$ infections, especially of HKU1 and NL63 in adults, reverse transcriptase PCR (RT-PCR) assays were performed on clinical specimens taken from adults with acute respiratory tract infections from 2005 to 2009 in Beijing, China. The clinical and epidemiological characteristics of the different $\mathrm{HCoV}$ infections (excluding SARS-CoV) were compared, and the phylogenetic features of $\mathrm{HCoV}$ strains were analyzed in this study.

\section{MATERIALS AND METHODS}

\section{Clinical Specimens}

Nasal and throat swabs were collected from adults with acute respiratory symptoms who visited the Fever Outpatient Clinic at Peking Union Medical College Hospital, Beijing, China. All samples were collected from May 2005 to April 2009, except in July and November of 2005. Patients over 14 years of age were selected for this study according to a set of criteria that included respiratory symptoms, acute fever (body temperature $\geq 38^{\circ} \mathrm{C}$ ), and normal or low leukocyte count, but not pulmonary abnormalities found by radiography [Ren et al., 2009]. Swabs were kept in viral transport medium and were stored at $-80^{\circ} \mathrm{C}$ prior to analysis.

\section{Clinical Data}

Symptoms, history of illness, results of clinical examination and laboratory investigations, and demographic data were recorded for each patient, using a standardized form. Clinical information of patients with $\mathrm{HCoV}$ infection was reviewed retrospectively from the records.

\section{RT-PCR Screening for Coronaviruses}

RNA and DNA were extracted from $200 \mu$ l viral transport medium, using NucliSens easyMAG ${ }^{\text {TM }}$ (bioMérieux, Marcy l'Etoile, France) according to the manufacturer's protocol [Boom et al., 1990]. Consensus primers targeting the RNA-dependent RNA polymerase (pol) gene, which generate an amplicon of about 440-bp in size, were used to screen all $\mathrm{HCoV}$ infections as described previously [Woo et al., 2005]. The analytic sensitivity of the RT-PCR for the detection of CoVs is 100 molecules. All PCR products were confirmed by sequencing. Various $\mathrm{HCoVs}$ in the samples, including OC43, 229E, NL63, and HKU1, were identified based on the alignment analysis of sequences of PCR products with the corresponding sequences of the pol gene of known $\mathrm{HCoVs}$ in the GenBank database, using BLAST software (http://blast.ncbi.nlm.nih.gov/Blast.cgi). The presence of other known respiratory viruses in the clinical specimens in addition to $\mathrm{HCoVs}$ including influenza virus types $\mathrm{A}, \mathrm{B}$, and $\mathrm{C}$, parainfluenza virus types $1-4$, enterovirus, rhinovirus, human metapneumovirus, adenovirus, and respiratory syncytial virus were also examined by RT-PCR or PCR as described previously [Ren et al., 2009].

\section{Phylogenetic Analysis}

Phylogenetic trees were constructed based on nucleotide sequences of PCR product corresponding to the partial pol gene of OC43, 229E, NL63, and HKU1, using the MEGA 4.0 software [Tamura et al., 2007]. The neighbor-joining method applying the Kimura twoparameter model with bootstrap values calculated from 1,000 replicates was used for phylogenetic analysis.

\section{Statistical Analysis}

Age, maximum body temperature, laboratory parameters, clinical features, and annual incidence of each $\mathrm{HCoV}$ infection were compared for patients using the $\chi^{2}$-test or Fisher's exact test for categorical variables, and Student's $t$-test for continuous variables. $P<0.05$ was considered significant.

\section{Sequence Accession Numbers}

The nucleotide sequences of the partial pol genes of the $\mathrm{HCoV}$ strains of OC43, 229E, HKU1, and NL63 identified in this study have been submitted to GenBank. The accession numbers are HM130737HM130814. GenBank accession numbers for reference sequences of OC43, 229E, NL63, HKU1A and B are NC005147, NC002645, NC005831, NC006577, and AY884001, respectively.

\section{RESULTS \\ Prevalence of HCoV Infections}

Totally 8,396 patients with ages ranging from 14 to 97 years old (median 30 years; mean 35.5 years) were enrolled in this study. Specimens were collected from both female $(4,538 ; 54 \%)$ and male $(3,858 ; 46 \%)$ patients. $\mathrm{HCoV}$ RNA was detected in $87(1 \%)$ of 8,396 patients. Based on the BLAST and phylogenetic analysis of the sequences of PCR products, 50 ( $0.6 \%$ of the total) patients were positive for OC43, $15(0.2 \%)$ for $229 \mathrm{E}$, 
TABLE I. Human Coronavirus (HCoV)-Positive Cases Detected in Adult Patients From May 2005 Through April 2009

\begin{tabular}{|c|c|c|c|c|c|}
\hline \multirow[b]{2}{*}{$\mathrm{HCoV}$} & \multicolumn{5}{|c|}{ Year } \\
\hline & $2005(\mathrm{n}=1,156)$ & $2006(\mathrm{n}=179)$ & $2007(\mathrm{n}=2,214)$ & $2008(\mathrm{n}=1,367)$ & $2009(\mathrm{n}=480)$ \\
\hline $\mathrm{OC} 43^{\mathrm{a}}$ & $6(0.5)^{b}$ & $6(0.2)$ & $33(1.5)$ & $2(0.2)$ & $3(0.6)$ \\
\hline $229 \mathrm{E}$ & $6(0.5)$ & 0 & $3(0.1)$ & 0 & $6(1.3)$ \\
\hline HKU1 & $1(0.1)$ & $8(0.3)$ & $1(0.1)$ & $3(0.2)$ & $1(0.2)$ \\
\hline NL63 & $2(0.2)$ & $2(0.1)$ & $4(0.2)$ & 0 & 0 \\
\hline Total cases $^{\mathrm{a}}$ & $15(1.3)$ & $16(0.5)$ & $41(1.9)$ & $5(0.4)$ & (2.1) \\
\hline
\end{tabular}

${ }^{\mathrm{a}} \chi^{2}=35.602, P<0.001$.

${ }^{\mathrm{b}}$ Numbers in parentheses indicate the percentages of positive infection in total samples.

$14(0.2 \%)$ for HKU1, and $8(0.1 \%)$ for NL63. Age of $\mathrm{HCoV}$-positive patients ranged from 14 to 90 years old (median 39 years; mean 43.5 years). The ratio of male:female $(0.91: 1.15)$ patients with $\mathrm{HCoV}$ infections showed no significant difference.

The detection rates of OC43, 229E, HKU1, and NL63 in the subjects are summarized in Table I. The overall detection rates of $\mathrm{HCoVs}$ varied significantly during the years of the study period $\left(2005-2009 ; \chi^{2}=35.602\right.$, $P<0.001$ )

Co-detection with other known respiratory viruses was found in 11 cases: nine with upper and two with lower respiratory tract infections. Rhinovirus, enterovirus, parainfluenza virus, and influenza virus were detected with $\mathrm{HCoV}$ strains OC43, 229E, and HKU-1, but not with NL63. Co-detection with parainfluenza virus type 3 and enterovirus was also found in two cases of lower respiratory tract infections. The details of codetection with other respiratory viruses for the various $\mathrm{HCoVs}$ are presented in Table III.

\section{Seasonality of HCoV Infections}

The study period covered 4 consecutive years, from May 2005 to April 2009. The seasonal distribution of HCoVs varied during the study period (Fig. 1). The detection rates of $\mathrm{HCoVs}$ spiked every 2 years, that is, in October 2005, June 2007, and April 2009. OC43 was detected in all of the studied years, with the highest rates found in June 2007. No positive cases were found in winter season (November-February) of year 2005 to 2007. 229E was detected mainly in October of 2005,
October and November of 2007, and April of 2009, but was not detected in 2006 and 2008 . HKU1 was detected in every year from 2005 to 2009, with the highest rates found in May and July 2006, and in February 2008. NL63 appeared sporadically during the study period in August-December in 2005-2007. NL63 was not detected in any spring season (March-May) during the study period; nor was it found in 2008 or during the period from January to April 2009.

\section{HCoV Infections in Different Age Groups}

$\mathrm{HCoV}$ infection was detected in all age groups, but the detection rate varied significantly $\left(\chi^{2}=43.569\right.$, $P<0.001)$. A higher rate of OC43 infection was detected in the age group $>65$ years. 229E and HKU1 were detected mainly in elderly adults, and NL63 seemed mainly to affect younger and elderly adults; however, there were not enough positive cases to obtain meaningful statistical data (Table II).

\section{Clinical Characteristics of HCoV Infections}

Of the $87 \mathrm{HCoV}$-positive patients, 79 (90.8\%) had upper respiratory tract infections, and $8(9.1 \%)$ had lower respiratory tract infections, that is, pneumonia and bronchiolitis with an increased number or density of lung markings apparent on chest radiograph. The incidence of lower respiratory tract infections in patients infected with the HKU-1 strain of $\mathrm{HCoV}$ (14.3\%) was higher than that of patients infected with OC43 (10\%) or NL63 (12.5\%), but these incidences were

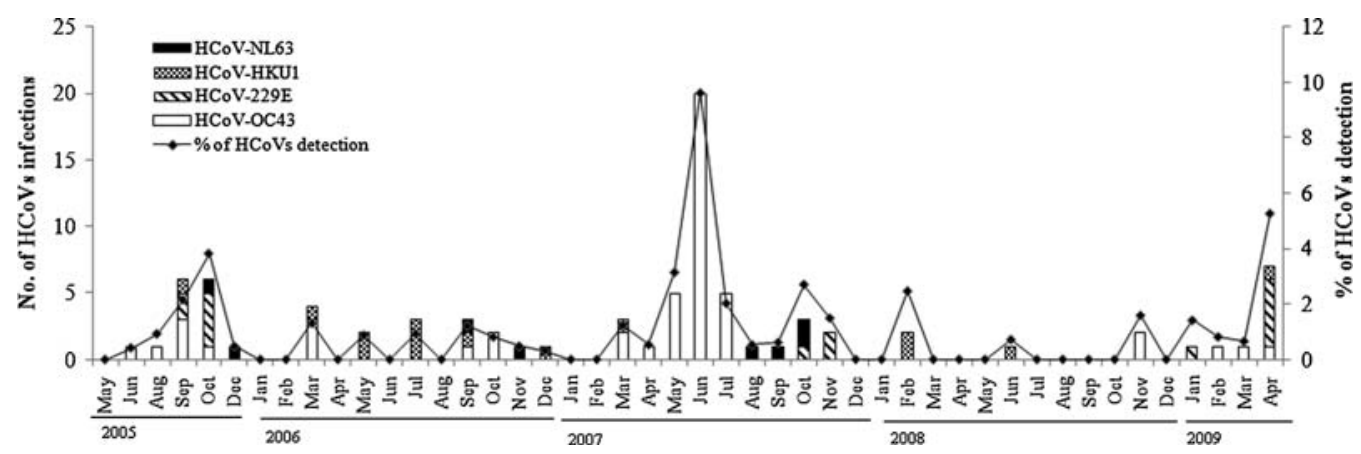

Fig. 1. Number and detection rate of human coronavirus positive respiratory samples during the study period. The bar graph indicates the number of OC43, 229E, NL63, and HKU1 positive cases, and the line graph indicates the total detection rate of human coronavirus in each month. 
TABLE II. Age Distribution of Human Coronavirus Infections in Adults With Acute Respiratory Tract Infections

\begin{tabular}{|c|c|c|c|c|}
\hline & $\leq 25$ years & $26-65$ years & $>65$ years & Total $(\%)$ \\
\hline No. of detected & 2,769 & 5,020 & 607 & 8,396 \\
\hline $\mathrm{OC} 43$ & $11(1.0)^{\mathrm{a}}$ & $24(0.8)$ & $15(3.6)$ & $50(0.6)$ \\
\hline $229 \mathrm{E}$ & $6(0.4)$ & $8(0.5)$ & $1(2.5)$ & $15(0.2)$ \\
\hline HKU1 & $5(0.2)$ & $5(0.1)$ & $4(0.7)$ & $14(0.2)$ \\
\hline NL63 & $5(0.2)$ & $1(0.02)$ & $2(0.3)$ & $8(0.1)$ \\
\hline Total $(\%)^{\mathrm{b}}$ & $27(1.0)$ & $38(0.8)$ & $22(3.6)$ & $87(1.0)$ \\
\hline
\end{tabular}

${ }^{a}$ Numbers in parentheses indicate the percentages of positive infection in total samples.

${ }^{\mathrm{b}} \chi^{2}=43.569, P<0.001$.

not significantly different. No patient infected with $229 \mathrm{E}$ was diagnosed with a lower respiratory tract infection in this study. Furthermore, there were few meaningful differences between clinical presentation and outcome of different $\mathrm{HCoV}$ infections. The maximum body temperature (mean $\pm \mathrm{SD}$ ) of patients was similar for different $\mathrm{HCoV}$ infections: OC43 (38.4 \pm $\left.0.5^{\circ} \mathrm{C}\right), 229 \mathrm{E}\left(38.4 \pm 0.4^{\circ} \mathrm{C}\right)$, HKU1 $\left(38.3 \pm 0.4^{\circ} \mathrm{C}\right)$, and NL63 $\left(38.6 \pm 0.6^{\circ} \mathrm{C}\right)$. Other symptoms frequently encountered included runny nose $(71.8 \%)$, headache (69\%), muscle pain $(67.8 \%)$, sore throat $(67.8 \%)$, chills (67.8\%), sneezing (62.1\%), and cough (49.4\%). Vomiting was observed more frequently in patients infected with $229 \mathrm{E}$ than in those infected with HKU1 or NL63 in this study (Table III).

Peripheral blood counts indicated that $84(96.6 \%)$ of the $87 \mathrm{HCoV}$-positive patients had no evidence of leucocytosis (Table III). In 229E-positive patients, the mean leukocyte count was lower than that in patients with other HCoV infections (Student's $t$-test, $P=0.013$ ).
No significant difference in the percentage of neutrophilic granulocytes, mean lymphocyte count, or percentage of lymphocytes was found among the patients infected by various $\mathrm{HCoV}$ strains.

\section{Phylogenetic Analysis of HCoV Strains}

Phylogenetic trees were constructed based on the alignment analysis of a 381-nucleotide fragment of the $\mathrm{HCoV}$ pol gene. All strains of 229E, NL63, and HKU1 identified in this study were included in the phylogenetic analysis. Sequences that showed $100 \%$ nucleotide identity were excluded, leaving 13 of the 50 OC43 strains to be further analyzed. OC43 had 97.8-100\% and $98.3-100 \%$ identity, respectively, for the nucleotide and the amino acid sequences. $229 \mathrm{E}$ had $98.6-100 \%$ and 98.4-100\%, HKU1A had $98.9-100 \%$ and $99.2-100 \%$, HKU1B had 98.9-100\% and 98.4-100\%, and NL63 had 98.6-100\% and $97.6-100 \%$ nucleotide and amino acid identity, respectively. No significant differences

TABLE III. Clinical Characteristics of Patients With Human Coronavirus (HCoV) Infections

\begin{tabular}{|c|c|c|c|c|}
\hline \multirow[b]{2}{*}{ Parameters } & \multicolumn{4}{|c|}{$\mathrm{HCoV}(\%)$} \\
\hline & OC43 & $229 \mathrm{E}$ & HKU1 & NL63 \\
\hline No. of patients & 50 & 15 & 14 & 8 \\
\hline Age range (year) & $14-90$ & $14-68$ & $24-78$ & $15-85$ \\
\hline Age mean/median (year) & $47.3 / 46$ & $37.9 / 36$ & $41.2 / 27.5$ & $34.6 / 18.5$ \\
\hline Gender $(\mathrm{M} / \mathrm{F})$ & $16 / 34$ & $6 / 9$ & $7 / 7$ & $6 / 2$ \\
\hline URTI & $45(90.0)^{\mathrm{a}}$ & $15(100)$ & $12(85.7)$ & $7(87.5)$ \\
\hline LRTI & $5(10.0)$ & 0 & $2(14.3)$ & $1(12.5)$ \\
\hline \multicolumn{5}{|l|}{ Clinical symptoms } \\
\hline Cough & $26(52.0)$ & $7(46.7)$ & $6(42.9)$ & $4(50.0)$ \\
\hline Sputum production & $6(12.0)$ & $3(20.0)$ & 0 & $2(25.0)$ \\
\hline Headache & $34(68.0)$ & $11(73.3)$ & $9(64.3)$ & $6(75.0)$ \\
\hline Muscle pain & $29(58.0)$ & $12(80.0)$ & $12(85.7)$ & $6(75.0)$ \\
\hline Sore throat & $33(66.0)$ & $12(80.0)$ & $8(57.1)$ & $6(75.0)$ \\
\hline Chilly & $37(74.0)$ & $12(80.0)$ & $11(78.6)$ & $6(75.0)$ \\
\hline Vomiting & $1(2.0)$ & $12(80.0)$ & 0 & 0 \\
\hline Runing nose & $36(72.0)$ & $12(80.0)$ & $9(64.3)$ & $5(62.5)$ \\
\hline Sneezing & $30(60.0)$ & $12(80.0)$ & $8(57.1)$ & $4(50.0)$ \\
\hline \multirow{6}{*}{$\begin{array}{l}\text { Peripheral blood tests } \\
\text { Mean leukocyte count }\left(\times 10^{9} / \mathrm{L}\right) \\
\text { Co-detection }\end{array}$} & & & & \\
\hline & $7.5 \pm 1.6$ & $6.5 \pm 1.8^{\mathrm{b}}$ & $8.1 \pm 1.7$ & $8.1 \pm 1.8$ \\
\hline & $5(10.0)$ & $4(26.7)$ & $2(14.3)$ & 0 \\
\hline & $\mathrm{EV}(\mathrm{n}=2)$ & $\operatorname{HRV}(\mathrm{n}=2)$ & $\operatorname{HRV}(\mathrm{n}=1)$ & \\
\hline & PIV3 $(n=2)$ & IFVA $(\mathrm{n}=1)$ & PIV3 $(\mathrm{n}=1)$ & \\
\hline & $\mathrm{EV}+\operatorname{HRV}(\mathrm{n}=1)$ & $\operatorname{IFVB}(\mathrm{n}=1)$ & & \\
\hline
\end{tabular}

LRTI, lower respiratory tract infection; URTI, upper respiratory tract infection.; PIV, parainfluenza virus; EV, enterovirus; IFV, influenza virus; HRV, human rhinovirus.

The numbers in parentheses indicate the percentages of positive infection in total samples.

btudent's $t$-test: $P=0.013$. 
OC43 lab (nt. 15204-15583)

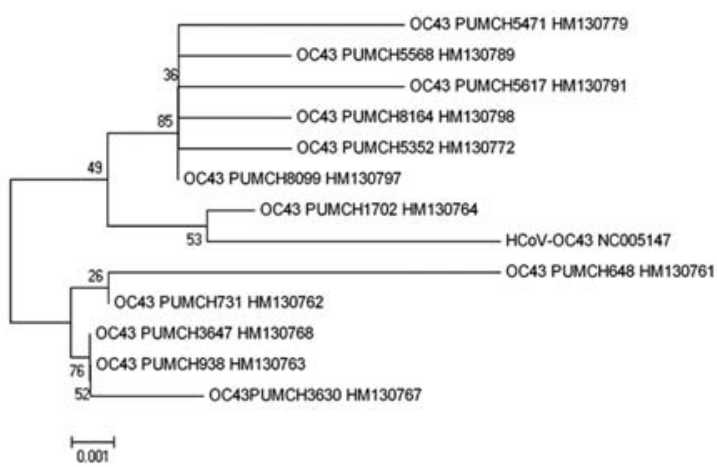

HKU1A lab (nt. 15460-15840) HKU1B lab (nt. 15454-15834)

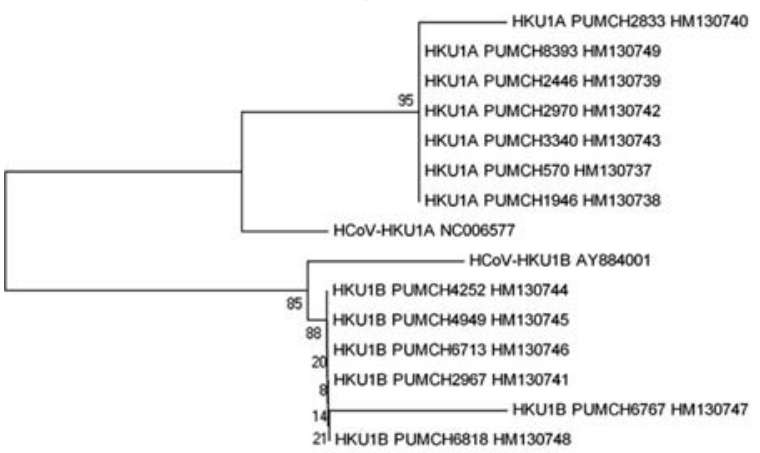

000
229E lab (nt. 14296-14674)

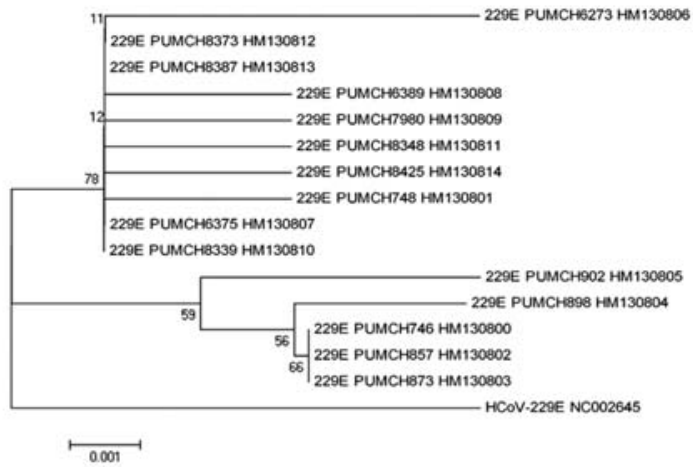

NL63 lab (nt. 14296-14674)

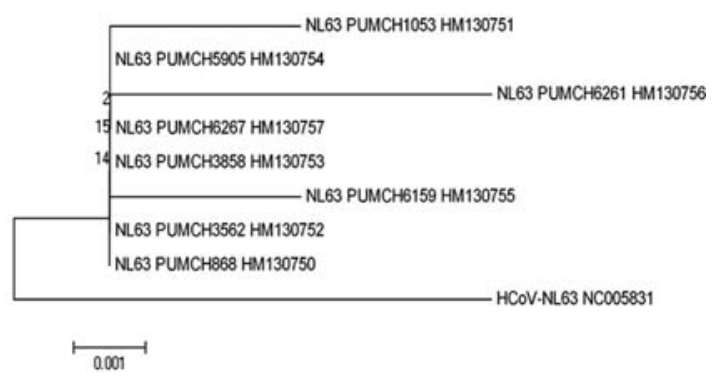

Fig. 2. Phylogenetic analysis of human coronavirus based on the partial sequence of the gene ORF $1 a b$. Phylogenetic trees were constructed based on nucleotide sequences of PCR products corresponding to the partial pol gene of OC43, 229E, NL63, and HKU1, analyzed by MEGA4.0 software using the distance method and the neighbor-joining algorithm with Kimura 2 parameters. Each strain from this study is indicated by a specific identification code (PUMCH) followed by the patient number and GenBank accession number. The GenBank accession numbers of the reference sequences of OC43, 229E, NL63, HKU1A and B were NC005147, NC002645, NC005831, NC006577, and AY884001, respectively. Scale bar indicates nucleotide substitutions per site.

were observed between $\mathrm{HCoV}$ strains identified in different years and seasons (Fig. 2.).

\section{DISCUSSION}

This study reports the prevalence and clinical presentations of $\mathrm{HCoV}$ infections in Chinese adults with symptoms of respiratory tract infections over a 4-year period. $\mathrm{HCoV}$ infections were found to be responsible for $1 \%$ of all cases of acute respiratory tract infections during the study period. OC43 strain led to the most prevalent $\mathrm{HCoV}$ infection $(0.6 \%)$, followed by $229 \mathrm{E}$ $(0.2 \%)$, HKU1 $(0.2 \%)$, and NL63 $(0.1 \%)$. The prevalence of $\mathrm{HCoV}$ infections in this study is lower than that in previous studies, in which detection rate of $\mathrm{HCoV}$ ranges from $2.1 \%$ to $5.7 \%$ [Gerna et al., 2006; Lau et al., 2006; Pierangeli et al., 2007; Bellei et al., 2008; Gorse et al., 2009; Leung et al., 2009]. Several factors may account for this disparity: (1) the subjects recruited in this study were adult outpatients whereas those in other studies were mainly hospitalized children [Gerna et al., 2006; Lau et al., 2006; Pierangeli et al., 2007; Leung et al.,
2009] or adults with underlying diseases [Lau et al., 2006; Bellei et al., 2008; Gorse et al., 2009]; (2) the viral infection rate from nasal and throat swabs used in this study may be lower than that of nasopharyngeal aspirates used in other studies [Lambert et al., 2008; Meerhoff et al., 2010]; and (3) differences in study time frame and geographical area [Lau et al., 2006].

Previous reports have shown that the infections by $229 \mathrm{E}$ and OC43 strains are highest during the winterspring seasons and can recur every $2-4$ years [McIntosh et al., 1970; Monto and Lim, 1974; Shao et al., 2007]. Our results for infection rates of $\mathrm{OC} 43$ and $229 \mathrm{E}$ are different from those of previous reports, which may be due to the geographic location and the alternating pattern of viral seasonality in our study. This study indicates that in China, OC43 infections peaked every other year, whereas $229 \mathrm{E}$ appeared every other year. Furthermore, OC43 was found mainly in summer and early autumn, and only a few cases appeared in November (winter season) 2008, whereas $229 \mathrm{E}$ was detected mainly in spring and summer. The seasonal distribution feature of HKU1 and NL63 infections from year to year is not very 
clear. As most of the previous studies covered only short periods, our understanding of the epidemiology for these subgroups is still incomplete. We found that HKU1 occurred in spring, early summer and winter, which concurred with a previous study of children in Hong Kong [Lau et al., 2006]. NL63 peaked in autumn as reported by others [Lau et al., 2006; Leung et al., 2009] but was absent in spring. Therefore, the seasonal pattern of NL63 infection appears to be similar to that of 229E. Taken together, these findings indicate that $\mathrm{HCoV}$ infections fluctuate by season although some $\mathrm{HCoV}$ subtypes such as OC43, 229E, and NL63 display biennial prevalence. However, continuous surveillance of $\mathrm{HCoV}$ infections over a long period is necessary to describe their temporal distribution more precisely.

Although the samples employed here were from immunocompetent adults, the age distribution for these patients was similar to that of immunocompromised adults or patients with severe underlying disease, such as chronic obstructive pulmonary disease [Lau et al., 2006; Varkey and Varkey, 2008]. There was a higher detection rate of all $\mathrm{HCoVs}$ in individuals $>65$ years of age, with a total positive rate of $3.6 \%$ in that age group. Of note, there was a lower detection rate $(0.02 \%)$ for NL63 in the 25-65 years age group, indicating that young adults are less affected by this strain. Because the number of patients who were positive for this virus was limited, further studies in different age groups should be carried out in the future.

$\mathrm{HCoV}$ infections elicited common symptoms such as fever, headache, muscle pain, sore throat, chills, runny nose, and cough. These symptoms were similar to those in other reports of $\mathrm{HCoV}$ infections [Bastien et al., 2005; Esper et al., 2005; Lau et al., 2006]. However, the clinical presentations were slightly different among OC43, 229E, NL63, and HKU1. In this study, vomiting was more common in 229E-positive patients but not in those infected by HKU1 and NL63 strains. Sputum production was also absent in HKU1 infections. During the study period, lower respiratory tract infections were found in individuals infected by OC43, HKU1, and NL63, but not in those with $229 \mathrm{E}$ infections. Because all the samples were taken from outpatients and they were not screened for co-detection with bacteria, an association between infection with different $\mathrm{HCoVs}$ and disease severity, and with different results from laboratory investigations such as peripheral blood tests, needs to be investigated further.

The simultaneous screening for common respiratory viruses allowed us to investigate co-infection of $\mathrm{HCoV}$ infected patients with other viral pathogens. Co-detection of other viruses was found in patients with OC43, 229E, and HKU1 infection. However, in 229E-infected patients, the co-detection rate was higher than those infected by other HCoVs. By contrast, no other viruses were detected in adult patients with NL63 infections in this study, although in children with acute respiratory tract infections NL63 was co-detected with other pathogens previously [Gerna et al., 2006]. Given that the number of NL63-positive cases was limited in this study, further investigation would help to clarify whether the difference of co-infection with other respiratory viruses in adults and children reflects the pathogenic feature of different $\mathrm{HCoVs}$.

The phylogenetics of $\mathrm{HCoVs}$ was analyzed based on the sequences of partial pol gene. However, this may not reflect the actual variation level of HCoVs. Further investigations are necessary to characterize the genetics, variation, and evolution of $\mathrm{HCoVs}$ by sequencing the whole viral genome or other representative genes, for example, spike and nucleocapsid, rather than the pol gene only.

In summary, this study reports a large-scale, detailed analysis of the prevalence and clinical presentations of different $\mathrm{HCoV}$ infections in adults with acute respiratory tract infections in Beijing, China during the period 2005 to 2009. All known HCoVs, including the recently identified HKU1 and NL63 strains, were detected in adults with acute respiratory tract infections. The results from this study should help to improve our understanding of the pathogenesis of $\mathrm{HCoVs}$ and provide information for evaluating the disease burden in clinics and disease control policies. However, given that the study population was limited and the number of $\mathrm{HCoV}$-positive samples studied was low, future investigations are needed to characterize the infections of the various $\mathrm{HCoVs}$ in adults more thoroughly.

\section{ACKNOWLEDGMENTS}

We thank the clinicians of the Peking Union Medical College Hospital for their assistance in sample collection.

\section{REFERENCES}

Bastien N, Anderson K, Hart L, Van Caeseele P, Brandt K, Milley D, Hatchette T, Weiss EC, Li Y. 2005. Human coronavirus NL63 infection in Canada. J Infect Dis 15:503-506.

Bellei N, Carraro E, Perosa A, Watanabe A, Arruda E, Granato C. 2008. Acute respiratory infection and influenza-like illness viral etiologies in Brazilian adults. J Med Virol 80:1824-1827.

Boom R, Sol CJ, Salimans MM, Jansen CL, Wertheim-van Dillen PM, van der Noordaa J. 1990. Rapid and simple method for purification of nucleic acids. J Clin Microbiol 28:495-503.

Chan CM, Tse H, Wong SS, Woo PC, Lau SK, Chen L, Zheng BJ, Huang JD, Yuen KY. 2009. Examination of seroprevalence of coronavirus HKU1 infection with S protein-based ELISA and neutralization assay against viral spike pseudotyped virus. J Clin Virol 45:54-60.

Dijkman R, Jebbink MF, El Idrissi NB, Pyrc K, Müller MA, Kuijpers TW, Zaaijer HL, van der Hoek L. 2008. Human coronavirus NL63 and 229E seroconversion in children. J Clin Microbiol 46:2368-2373.

Drosten C, Günther S, Preiser W, van der Werf S, Brodt HR, Becker S, Rabenau H, Panning M, Kolesnikova L, Fouchier RA, Berger A, Burguière AM, Cinatl J, Eickmann M, Escriou N, Grywna K, Kramme S, Manuguerra JC, Müller S, Rickerts V, Stürmer M, Vieth S, Klenk HD, Osterhaus AD, Schmitz H, Doerr HW. 2003. Identification of a novel coronavirus in patients with severe acute respiratory syndrome. N Engl J Med 348:1967-1976.

Esper F, Weibel C, Ferguson D, Landry ML, Kahn JS. 2005. Evidence of a novel human coronavirus that is associated with respiratory tract disease in infants and young children. J Infect Dis 191:492-498.

Fouchier RA, Hartwig NG, Bestebroer TM, Niemeyer B, de Jong JC, Simon JH, Osterhaus AD. 2004. A previously undescribed coronavirus associated with respiratory disease in humans. Proc Natl Acad Sci USA 101:6212-6216. 
Gerna G, Campanini G, Rovida F, Percivalle E, Sarasini A, Marchi A, Baldanti F. 2006. Genetic variability of human coronavirus OC43-, 229E-, and NL63-like strains and their association with lower respiratory tract infections of hospitalized infants and immunocompromised patients. J Med Virol 78:938-949.

Gibbs AJ, Gibbs MJ, Armstrong JS. 2004. The phylogeny of SARS coronavirus. Arch Virol 149:621-624.

Gorse GJ, O'Connor TZ, Hall SL, Vitale JN, Nichol KL. 2009. Human coronavirus and acute respiratory illness in older adults with chronic obstructive pulmonary disease. J Infect Dis 199:847-857.

Hamre D, Procknow JJ. 1966. A new virus isolated from the human respiratory tract. Proc Soc Exp Biol Med 121:190-193.

Holmes KV. 2001. Coronavirus. In: Knipe DM, Howley MD, editors. Fields virology Philadelphia, PA: Lippincott Williams and Wilkins. pp. 1187-1204.

Kuiken T, Fouchier RA, Schutten M, Rimmelzwaan GF, van Amerongen G, van Riel D, Laman JD, de Jong T, van Doornum G, Lim W, Ling AE, Chan PK, Tam JS, Zambon MC, Gopal R, Drosten C, van der Werf S, Escriou N, Manuguerra JC, Stöhr K, Peiris JS, Osterhaus AD. 2003. Newly discovered coronavirus as the primary cause of severe acute respiratory syndrome. Lancet 362:263-270.

Lai MM, Cavanagh D. 1997. The molecular biology of coronaviruses. Adv Virus Res 48:1-100.

Lambert SB, Whiley DM, O'Neill NT, Andrews EC Canavan FM, Bletchly C, Siebert DJ, Sloots TP, Nissen MD. 2008. Comparing nose-throat swabs and nasopharyngeal aspirates collected from children with symptoms for respiratory virus identification using real-time polymerase chain reaction. Pediatrics 122:e615-e620.

Lau SK, Woo PC, Yip CC, Tse H, Tsoi HW, Cheng VC, Lee P, Tang BS, Cheung CH, Lee RA, So LY, Lau YL, Chan KH, Yuen KY. 2006. Coronavirus HKU1 and other coronavirus infections in Hong Kong. J Clin Microbiol 44:2063-2071.

Leung TF, Li CY, Lam WY, Wong GW, Cheuk E, Ip M, Ng PC, Chan PK. 2009. Epidemiology and clinical presentations of human coronavirus NL63 in Hong Kong children. J Clin Microbiol 47:3486-3492

McIntosh K, Dees JH, Becker WB, Kapikian AZ, Chanock RM. 1967. Recovery in tracheal organ cultures of novel viruses from patients with respiratory disease. Proc Natl Acad Sci USA 57:933-940.

McIntosh K, Kapikian AZ, Turner HC, Hartley JW, Parrott RH, Chanock RM. 1970. Seroepidemiologic studies of coronavirus infection in adults and children. Am J Epidemiol 91:585-592.
Meerhoff TJ, Houben ML, Coenjaerts FE, Kimpen JL, Hofland RW, Schellevis F, Bont LJ. 2010. Detection of multiple respiratory pathogens during primary respiratory infection: Nasal swab versus nasopharyngeal aspirate using real-time polymerase chain reaction. Eur J Clin Microbiol Infect Dis 29:365-371.

Monto AS, Lim SK. The Tecumseh study of respiratory illness. VI. 1974.Frequency of and relationship between outbreaks of coronavirus infection. J Infect Dis 129:271-276.

Perlman S, Netland J. 2009. Coronaviruses post-SARS: Update on replication and pathogenesis. Nat Rev Microbiol 7:439-450.

Pierangeli A, Gentile M, Di Marco P, Pagnotti P, Scagnolari C Trombetti S, Lo Russo L, Tromba V, Moretti C, Midulla F, Antonell G. 2007. Detection and typing by molecular techniques of respiratory viruses in children hospitalized for acute respiratory infection in Rome, Italy. J Med Virol 79:463-468.

Ren L, Gonzalez R, Wang Z, Xiang Z, Wang Y, Zhou H, Li J, Xiao Y, Yang Q, Zhang J, Chen L, Wang W, Li Y, Li T, Meng X, Zhang Y, Vernet G, Paranhos-Baccalà G, Chen J, Jin Q, Wang J. 2009. Prevalence of human respiratory viruses in adults with acute respiratory tract infections in Beijing, 2005-2007. Clin Microbiol Infect 15:1146-1153.

Shao X, Guo X, Esper F, Weibel C, Kahn JS. 2007. Seroepidemiology of group I human coronaviruses in children. J Clin Virol 40:207-213.

Tamura K, Dudley J, Nei M, Kumar S. 2007. MEG A4: Molecular evolutionary genetics analysis (MEGA) software version 4.0. Mol Biol Evol 24:1596-1599.

Tyrrell DA, Bynoe ML. 1965. Cultivation of a novel type of common cold virus in organ cultures. Br Med J 1:1467-1470.

van der Hoek L. 2007. Human coronaviruses: What do they cause? Antivirol Ther 12:651-658.

van der Hoek L, Pyrc K, Jebbink MF, Vermeulen-Oost W, Berkhout RJ, Wolthers KC, Wertheim-van Dillen PM, Kaandorp J, Spaargaren J, Berkhout B. 2004. Identification of a new human coronavirus. Nat Med 10:368-373.

Varkey JB, Varkey B. 2008. Viral infections in patients with chronic obstructive pulmonary disease. Curr Opin Pulm Med 14:89-94.

Woo PC, Lau SK, Chu CM, Chan KH, Tsoi HW, Huang Y, Wong BH, Poon RW, Cai JJ, Luk WK, Poon LL, Wong SS, Guan Y, Peiris JS, Yuen KY. 2005. Characterization and complete genome sequence of a novel coronavirus, coronavirus HKU1, from patients with pneumonia. J Virol 79:884-895.

Woo PC, Lau SK, Huang Y, Yuen KY. 2009. Coronavirus diversity, phylogeny and interspecies jumping. Exp Biol Med (Maywood) 234:1117-1127. 